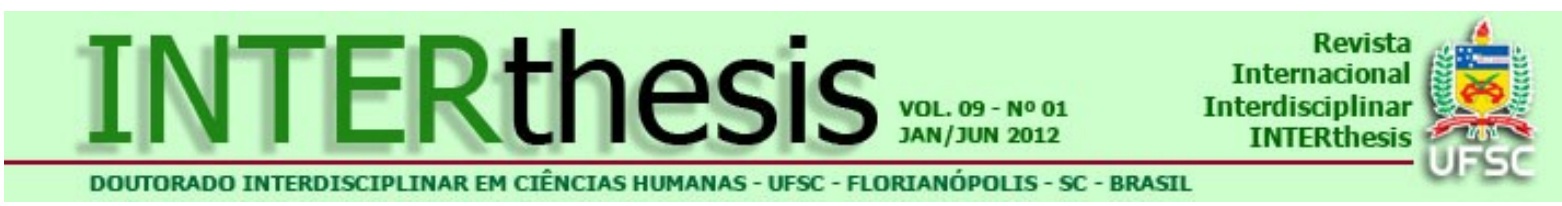

\title{
PROJETOS DE GRANDE ESCALA E CAMPOS SOCIAIS DE CONFLITO: CONSIDERAÇÕES SOBRE AS IMPLICAÇÕES SOCIOAMBIENTAIS E POLÍTICAS DA INSTALAÇÃO DE HIDRELÉTRICAS
}

\begin{abstract}
LARGE-SCALE PROJECTS AND FIELDS OF SOCIAL CONFLICTS: CONSIDERATIONS ON THE SOCIAL, ENVIRONMENTAL AND POLITICAL IMPLICATIONS OF THE INSTALLATION OF HYDROELECTRIC POWER PLANTS
\end{abstract}

\section{PROYECTOS DE GRAN ESCALA Y CAMPOS SOCIALES DE CONFLICTOS: CONSIDERACIONES SOBRE LAS CONSECUENCIAS SOCIOAMBIENTALES $Y$ POLÍTICAS EN LA INSTALACIÓN DE HIDRELÉCTRICAS}

Maria José Reis ${ }^{1}$

\begin{abstract}
RESUMO:
Apresento, neste artigo, uma retrospectiva histórica sobre a intervenção estatal na formação e atuação do setor elétrico brasileiro, bem como identifico efeitos socioambientais decorrentes da instalação de hidrelétricas, e analiso 0 encaminhamento de reivindicações de populações locais e regionais ocupantes dos espaços requeridos para a instalação destas usinas. Essas reivindicações, objeto de lutas e negociações, têm sido encaminhadas como "direitos", que vêm sendo negociados através do Movimento dos Atingidos por Barragens (MAB), iniciado na Bacia do Rio Uruguai (SC/RS) no final da década de 1970, contando atualmente com projeção nacional e internacional. Concluo constatando que as populações locais e regionais afetadas pelos processos de reestruturação territorial em face da instalação de hidrelétricas, a partir da privatização de parte do setor elétrico brasileiro, na década de 1990, têm enfrentado novos desafios decorrentes da atuação dos consórcios e instituições governamentais responsáveis, de um modo ou de outro, pelos referidos empreendimentos - incluindo a identificação e mitigação das questões socioambientais. Esses desafios, apontados em recentes trabalhos acadêmicos, têm sido avaliados como um significativo retrocesso no que concerne às negociações e soluções para as questões socioambientais decorrentes da instalação das obras em questão.
\end{abstract}

Palavras-chave: Hidrelétricas. Efeitos socioambientais. Campo social de conflito.

${ }^{1}$ Doutora em Ciências Sociais pela Universidade Estadual de Campinas (UNICAMP). Professora aposentada da UFSC, onde atua como pesquisadora, e Professora Titular na Universidade do Vale do Itajaí (UNIVALI). E-mail: masereis@hotmail.com

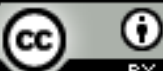

Esta obra foi licenciada com uma Licença Creative Commons - Atribuição 3.0 Não

Adaptada. 


\section{ABSTRACT:}

This article presents a historic retrospective on state intervention on the formation and performance of the Brazilian electricity sector. It also identifies social and environmental effects derived from the installation of hydroelectric power plants; along with the analysis of the claims of local and regional populations, occupants of territories required for the installation of such power plants. These claims, object struggles and negotiations have been forwarded as "rights" that are being negotiated through the Movimento dos Atingidos por Barragens (MAB) or Movement of the Affected by Dams, first started in the Basin of the Uruguai River (SC/RS), in Brazil, during the late 1970s and now with national and international projection. This article concludes by noting that the local and regional populations affected by the territorial relocation process as a consequence of the hydroelectric power plant's installation, starting from the privatization of part of the Brazilian electricity sector during the 90ths, have faced new challenges originated from the activities of consortia and government institutions, responsible in one way or another, by such developments including the identification and mitigation of social and environmental issues. These challenges, pointed out in recent academic researches, have been evaluated with significant setback in relation to negotiations and solutions to social and environmental issues arising from the installation of these power plants.

Keywords: Hydroelectric power plants. Social and environmental effects. Fields of social conflict.

\section{RESUMEN:}

En este artículo presento una retrospectiva histórica sobre la intervención estatal en la formación y actuación del sector eléctrico brasileño e identifico, también, los efectos socioambientales provenientes de la instalación de centrales hidroeléctricas. Se analiza el encaminamiento de las reivindicaciones de las poblaciones locales y regionales que ocupan los espacios requeridos para la instalación de estas usinas. Estas reivindicaciones, objeto de luchas y negociaciones, han sido tratadas como "derechos" que están siendo negociados a través del Movimento dos Atingidos por Barragens (MAB), iniciado en la Cuenca del Río Uruguay (SC/RS) a fines de la década del 70 y contando actualmente con proyección nacional e internacional. Concluyo constatando que las poblaciones locales y regionales afectadas por los procesos de reestructuración territorial debido a la instalación de represas hidroeléctricas, a partir de la privatización de parte del sector eléctrico brasileño en la década del 90, han enfrentado nuevos desafíos que resultan de la actuación de los consorcios e instituciones gubernamentales responsables, de un modo o de otro, por los referidos emprendimientos, incluyendo la identificación y mitigación de las cuestiones socioambientales. Estos desafíos, presentados en recientes trabajos académicos, han sido evaluados como un significativo retroceso en lo que se refiere a las negociaciones y soluciones para los asuntos socioambientales provenientes de la instalación de las obras en cuestión.

Palabras clave: Hidroeléctricas. Efectos socioambientales. Campo social de conflictos.

De acordo com inúmeras pesquisas nacionais e internacionais, os denominados "projetos de grande escala" (RIBEIRO, 1985), ou "grandes projetos de 
investimento" (VAINER, 2007), parte de projetos governamentais de desenvolvimento voltados para a disponibilidade de infraestrutura, entre os quais a instalação de hidrelétricas, desencadeiam processos socioambientais de extrema complexidade, compreendendo tanto aspectos técnicos quanto sociais e políticos. Conforme Ribeiro (idem), estes processos dependem de grandes movimentações de capital e de mão-de-obra, envolvendo um número significativo de agentes sociais. Dentre estes agentes destacam-se as instituições financeiras nacionais e internacionais; os consórcios públicos e privados responsáveis pelo projeto, execução e funcionamento destas obras; as instituições estatais responsáveis pelas questões ambientais e regulatórias; as empresas de consultoria socioambiental; técnicos e trabalhadores para a execução das obras de infraestrutura necessárias para a instalação das usinas de geração de energia e, de modo especial, uma gama de populações locais - rurais e urbanas, incluindo populações indígenas e kilombolas - ocupantes das áreas a serem requisitadas para a instalação de cada uma destas obras e por vezes suas assessorias políticas que têm intermediado a organização de movimentos sociais questionadores destes projetos.

Por outro lado, como resultante da conjugação destes e de outros agentes sociais, tem sido afirmado (REIS, 1998; REIS; BLOEMER, 2001), com base em diferentes autores ${ }^{2}$ que estudaram mudanças socioculturais decorrentes de processos de reterritorialização relacionados às ocupações coloniais, que a instalação de hidrelétricas, como de resto todas as obras de infraestrutura voltadas para projetos de desenvolvimento econômico (RIBEIRO, 2008), formam campos sociais marcados por conflitos, tendo em vista as perspectivas e interesses diversificados e até contrastantes dos múltiplos agentes neles envolvidos, e de relações de poder entre eles, cujo desfecho depende da configuração e da atuação de todas as forças sociais em jogo.

Em síntese, trata-se de eventos marcados por relações assimétricas entre os participantes do referido campo, que manifestam diferentes posicionamentos em relação aos ganhos e perdas decorrentes da instalação destas obras, aspectos que serão objeto de reflexão no presente artigo. Nele será apresentada uma retrospectiva histórica sobre a intervenção estatal na formação e atuação do setor elétrico brasileiro, bem como identificados os efeitos socioambientais decorrentes da

2 Veja-se, entre outros, Gluckman (apud OLIVEIRA FILHO, 1988), Bourdieu; Sayad (1964), e Sahlins (1981). 
instalação de hidrelétricas, e analisadas as reivindicações de populações locais e regionais ocupantes dos espaços requeridos para a instalação destas usinas. Estas reivindicações, objeto de lutas e negociações, têm sido encaminhadas como "direitos" a serem atendidos para mitigação das perdas e danos decorrentes de sua condição de atingidos ${ }^{3}$. Direitos que vem sendo negociados através do Movimento dos Atingidos por Barragens (MAB), iniciado na Bacia do Rio Uruguai (SC/RS) no final da década de 1970, contando atualmente com projeção nacional e internacional.

\section{PROJETOS DE DESENVOLVIMENTO E A INSTITUCIONALIZAÇÃO DO SETOR ELÉTRICO BRASILEIRO}

Em uma breve retrospectiva histórica sobre a produção de energia elétrica no Brasil, dois aspectos merecem destaque. Por um lado, o fato de que é possível identificar nesta história quatro etapas distintas, a saber, do final do século XIX até 1930; de 1930 até 1964; desta data até 1990, e a partir daí até os dias atuais. Por outro lado, chama a atenção, como um aspecto recorrente que atravessa todas as etapas a partir de 1930, o fato que desde então registra-se o atrelamento da produção de energia elétrica a planos e projetos de desenvolvimento propostos e assumidos total ou parcialmente pelo Estado brasileiro, ator central nos respectivos campos sociais de conflitos que estes projetos desencadearam e desencadeiam, embora com diferentes configurações e perspectivas.

De fato, a gestão e controle do Estado sobre os usos da água para diferentes fins, inclusive para a produção de energia elétrica, foram assumidos por instâncias governamentais brasileiras preocupadas com a modernização do país, ou seja, mais precisamente com seu desenvolvimento econômico, através do fomento das atividades industriais. Assim é que uma das principais metas das sucessivas gestões presidenciais, desde a referida gestão de Getúlio Vargas, era e foi ampliar a infraestrutura do país, em relação a diferentes aspectos, entre os quais o de geração de energia elétrica.

\footnotetext{
${ }^{3}$ Trata-se, em primeira mão, de uma autodesignação assumida por pequenos produtores rurais da região do Alto Uruguai (SC/RS), através da constituição da Comissão Regional de Atingidos por Barragens (CRAB), da qual se originou o Movimento dos Atingidos por Barragens (MAB), a partir da atribuição inicial feita pela ELETROSUL à população a ser deslocada das áreas reivindicadas para a instalação de hidrelétricas (REIS, 1998).
} 
O mesmo não ocorreu no primeiro destes períodos ou etapas que se inicia no final do século XIX, no qual foram instaladas as pioneiras usinas brasileiras para a produção de energia elétrica, por iniciativas do setor privado, dentre as quais a primeira hidrelétrica, em Minas Gerais, no ano de 1883. Estas iniciativas, como as subsequentes ao longo das três primeiras décadas do século $X X$, aos poucos foram se ampliando, através da participação de empresas estrangeiras (norte-americanas, francesas, argentinas, canadenses, entre outras).

A partir da década de 1930, contudo, com a gestão presidencial de Getúlio Vargas, que marca o início da segunda etapa em relação à produção de energia elétrica no país, que se encerra com o advento da Ditadura Militar, o Estado brasileiro passou a desenvolver uma série de iniciativas institucionais com a finalidade de montar um aparato estatal nacional e posteriormente também estadual, destinado ao controle dos recursos à geração e distribuição, dentre outras, de energia elétrica.

Como parte das iniciativas voltadas para um projeto de desenvolvimento destinado a criar infraestrutura e dar suporte ao processo de industrialização do país, foi criado em 1930 o Ministério do Trabalho, Indústria e Comércio, e em 1933 o Departamento Nacional de Produção Mineral, este último com uma Divisão de Águas para tratar, entre outras atribuições, da exploração de energia elétrica; em 1934 foi elaborado o Código de Águas, com um conjunto de princípios e normas sobre a gestão deste recurso; em 1939 foi criado o Conselho Nacional de Águas e Energia Elétrica, subordinado à Presidência da República. Esta centralização administrativa foi referendada e reforçada nas Constituições Federais de 1934 e 1937, mas também foram estabelecidas regras para os governos estaduais organizarem seus próprios serviços técnicos e administrativos a este respeito. (DIAS et al, 1988).

De acordo com Bôa Nova (apud REIS, 1991), embora a partir de iniciativas do governo federal tenha sido considerável a expansão da oferta de energia elétrica durante a década de 1930, o crescimento industrial que ocorreu no país desta década em diante, e as dificuldades de expansão da potência instalada em função da Segunda Guerra Mundial acabaram por criar uma situação de crise de fornecimento desta energia, resultando na mobilização dos setores produtivos industriais para pressionar o governo central com vistas a ampliação da citada oferta. 
Assim é que em 1946 foi elaborado o Plano Nacional de Eletrificação, com base na orientação de consultores norte-americanos, identificados como membros da "Missão Cook", contratados pelo governo federal para ajudar a planejar a economia com vistas ao desenvolvimento do país. Embora o relatório da referida Missão tenha recomendado a instalação de médias e pequenas usinas hidrelétricas, a opção deste Plano Nacional e de planos posteriores foi a implantação de grandes usinas, dentre as quais as do complexo de hidrelétricas de Paulo Afonso, cuja primeira barragem foi instalada no rio $S$. Francisco (BA) pela também primeira empresa de eletricidade brasileira - a Companhia Hidroelétrica do São Francisco (CHESF) - criada pelo governo federal em 1948. (VIANA, 1989).

De 1950 ao início da década seguinte, especialmente durante a gestão presidencial de Juscelino Kubitschek (1956-1961) através da implementação de seu Plano de Metas visando o desenvolvimento industrial do país, a capacidade instalada de energia hidráulica se amplia de 1.584 para $3.642 \mathrm{MWs}$. Este incremento na produção de energia por parte do governo federal foi possibilitado pela injeção de recursos externos, através de vultosos empréstimos internacionais que possibilitaram a instalação de várias usinas de grande porte, dentre as quais a de Três Marias (MG), Furnas (MG/SP), Ilha Grande e Jupiá, ambas instaladas no estado de São Paulo.

Em 1962, já na gestão presidencial de João Goulart, é instalada a Eletrobras integrando o Ministério das Minas e Energia. Apesar de proposta em 1953, no segundo mandato de Getúlio Vargas, no qual foi desenhado uma política nacional de energia e um Plano Nacional de Eletrificação, sua efetiva criação foi retardada devido a posições privatistas que dominavam o Congresso Nacional, a ponto deste Plano jamais ter sido aprovado (SANTOS; REIS, 2002).

Com o Golpe Militar que derrubou o governo de João Goulart, em 1964, iniciase a terceira etapa da história da eletricidade no Brasil, período de maior intervenção do Estado na economia nacional. Através da Eletrobras, definiu-se a Política Nacional do Meio Ambiente (Lei 6.038, de 1981) incluindo-se, deste modo, além da preocupação com a dimensão técnica de empreendimentos voltados para a produção de energia até então dominante, aspectos ambientais e sociais, por orientação e imposição de órgãos financiadores internacionais. Para tratar destes aspectos a Eletrobras criou, em 1986 o Conselho Nacional de Meio Ambiente (Conama), que através da Resolução 001/86, fixou os requisitos para a avaliação de 
impactos para o licenciamento de obras causadoras de alterações ambientais significativas, e neste mesmo ano editou o Manual de Estudos de Efeitos Ambientais dos Sistemas Elétricos. (ELETROBRAS, 1986).

Tornaram-se, assim, obrigatórios para os licenciamentos destas obras, entre as quais as hidrelétricas, a realização dos Estudos de Impacto Ambiental (EIA) e do Relatório de Impacto ao Meio Ambiente (RIMA) ${ }^{4}$. Do mesmo modo, através da Resolução 006/87, o Conama estabeleceu as diversas etapas do processo de licenciamento $^{5}$, e através da Resolução 009.87 garantiu a obrigatoriedade de audiências públicas ${ }^{6}$ para submeter o RIMA à opinião dos interessados, de um modo ou de outro, nas implicações socioambientais decorrentes das obras submetidas aos processos de licenciamento.

Constata-se também, através desta breve reconstituição histórica sobre a presença e a intervenção do Estado na produção de hidreletricidade, que esta intervenção, em termos institucionais, acentuou-se durante o período da Ditadura Militar. Foi igualmente durante este período que foram propostas e em parte instaladas grandes hidrelétricas como a de Sobradinho, iniciadas as de Itaparica, Itaipu, Tucuruí e Balbina, além de terem sido projetadas e iniciadas as etapas para a instalação de hidrelétricas em bacias hidrográficas nos estados de São Paulo e Paraná, na Bacia do rio Uruguai, (RS/PR) e em rios da Amazônia.

Com a privatização de parte do setor elétrico pelas gestões governamentais federais que se sucederam ao longo da década de 1990, inicia-se a quarta etapa da história brasileira da hidroeletricidade, que se prolonga até os dias atuais, e com ela determinadas reestruturações no setor elétrico brasileiro.

Esta reestruturação que diminuiu a possibilidade de gestão e controle estatal sobre a produção de energia elétrica de um modo geral, veio a interromper alguns ganhos, conquistados através de conflitos e de lutas para sua legitimação. Em outros termos, como afirma Vainer (2007), "Ao privatizar sem critérios empresas de

\footnotetext{
${ }^{4}$ Trata-se de uma versão simplificada do EIA, acessível ao público leigo, destinada à avaliação em audiências criadas com esta finalidade.

${ }^{5}$ De acordo com a referida Resolução do Conama, para a construção e instalação de uma usina hidrelétrica é necessária a obtenção pelo empreendedor de três licenças do órgão ambiental responsável (o IBAMA, no caso de barragens instaladas em rios interestaduais, ou o órgão estadual, nos casos de rios localizados em apenas um Estado) : a licença prévia, a de instalação e a de operação.

${ }^{6}$ Segundo o artigo $2^{\circ}$ da mesma Resolução, "a convocação de uma audiência pública para a discussão do EIA/RIMA faz-se quando: a) o órgão público ambiental 'julgar necessário'; b) houver solicitação de entidade civil; c) houver solicitação do Ministério Publico; d) houver solicitação por parte de 50 ou mais cidadãos".
} 
geração e distribuição de energia elétrica, ao favorecer de maneira atabalhoada a concessão de direitos de exploração de potenciais hidrelétricos a grupos privados, [...] a reestruturação colocou em risco muito do que havia sido conquistado em termos sociais e ambientais".

Do mesmo modo, ao longo da gestão do Ex-presidente Luiz Inácio Lula da Silva e da atual gestão da Presidenta Dilma Rousseff, vem ocorrendo a continuidade de projetos definidos em gestões federais anteriores, como os do Vale do Uruguai e da região Amazônica - entre os quais os do Complexo Hidrelétrico do Rio Madeira, e o de Belo Monte, no rio Xingu (PA) - como parte dos Planos de Aceleração do Crescimento (PAC 1 e 2).

Em síntese, como resultado da simbiose entre projetos de desenvolvimento e a produção de hidroeletricidade através de grandes barragens contamos, atualmente, com duas dentre as 10 maiores UHE do mundo: a de, Itaipu, segunda maior depois da UHE Três Gargantas, instalada na China, e a de Tucuruí. Fará parte também desta lista, quando concluída, em terceiro ou quarto lugar, a UHE de Belo Monte, em processo de instalação no rio Xingu (PA).

Por outro lado, o que se constata, em linhas gerais, desde o início da intervenção estatal na produção de hidroeletricidade, é que apesar de dispositivos e orientações adequados e bem elaborados contidas em documentos como os da Eletrobras (1986 e 1992), enfatizados por Vainer (2008), na prática, a priorização dos aspectos técnicos e financeiros com as obras para este fim entra em descompasso com a pouca atenção que chega à irresponsabilidade, inclusive de órgão públicos, para com uma série de prejuízos ou efeitos negativos socioambientais provocados pelo processo de instalação das usinas voltadas para este fim, aspectos que serão tratados a seguir.

\section{CONSEQUÊNCIAS SOCIOAMBIENTAIS DA INSTALAÇÃO DE HIDRELÉTRICAS}

Entre os múltiplos desdobramentos e efeitos da instalação de usinas hidrelétricas, Souza $(1988$, p. 124) destaca que a instalação dessas obras desencadeia um processo de apropriação econômica dos recursos hídricos e ambientais que implicam sempre em um prévio processo de expropriação e de reconversão da base material e social da região onde se instala o empreendimento. Ou seja, provoca a necessidade de uma reordenação territorial local e regional, que 
implica em mudanças espaciais, necessárias para a instalação e o funcionamento das hidrelétricas. Dentre estas mudanças destaca-se a instalação do canteiro de obras para a construção das obras destinadas ao barramento do rio; para a formação do reservatório da usina; de canais de reorientação dos cursos de água; da instalação das dependências para a instalação da casa de força da usina e das vilas para os trabalhadores, enfim de toda uma infraestrutura para sua instalação. Trata-se, de fato, de "limpar" o espaço local, conforme Sigaud (1988), através do desmatamento das áreas requeridas para o empreendimento, da retirada de parte da fauna destes espaços, quando possível, e de modo todo especial das populações humanas ocupantes destas áreas. Ocorre, também, a transformação e ocupação de espaços destinados à construção e instalação de outras obras de infraestrutura, como estradas, pontes e linhas de transmissão da energia elétrica produzida.

Considerando, portanto, que comumente os espaços necessários à instalação e ao funcionamento de obras desta natureza não são "espaços vazios", mas alojam diferentes segmentos sociais, torna-se indispensável a migração compulsória das populações que historicamente vinham ocupando esses espaços.

Do ponto de vista social, no caso das populações rurais, mais comumente vítimas dos processos em pauta, trata-se da destruição e perda do acesso a áreas de produção e captação de recursos naturais e de postos de trabalho, do rompimento do tecido social comunitária, além da mutilação ou total transformação dos espaços simbolicamente mapeados, tais como bens comunitários - entre outros, escolas, igrejas, cemitérios, áreas de sociabilidade e de lazer, - compreendendo também aspectos cognitivos, míticos e afetivos (REIS; BLOEMER, 2001, p. 12).

Em outros termos, como lembra Souza (1988, p. 124)

O que está em jogo não é apenas de ordem material e jurídica; há toda uma dimensão histórica e cultural que se vê seriamente ameaçada, quando não destruída, que não se materializa necessariamente em terra, habitação, benfeitorias ou produção alimentar.

Por outro lado, é indispensável destacar que não somente a população compulsoriamente removida das áreas requisitadas por esses projetos deve ser considerada "atingida"7. A rigor, a implantação de tais projetos, para além de seus beneficiários - entre os quais grupos empresariais e industriais agrupados em

\footnotetext{
${ }^{7}$ Uma discussão sobre esta categoria pode ser encontrada, entre outros, em Vainer (2008), que informa sobre a ampliação deste conceito em um documento emitido pela Eletrobras, em 1986. Em termos legais, entretanto, a maior abrangência desta categoria só foi definida em 2010, através do Decreto Presidencial 7.342.
} 
consórcios de empreendedores, neles incluindo esferas estatais - acaba por criar milhares de outras vítimas, entre elas as populações que permanecem nos espaços locais e regionais. Estas têm igualmente seu patrimônio natural e seu espaços mutilados, tanto a montante como a jusante do rio barrado. Assim é que "para quem fica" - que nos termos do MAB, "também é atingido" - o afastamento das famílias que migraram compulsoriamente, entre eles por vezes parentes, vizinhos, amigos, membros de associações comunitárias de vários tipos, provoca o esfacelamento de suas redes de sociabilidade locais e por vezes, inclusive, a impossibilidade de funcionamento de certos serviços básicos como o das escolas, pelo número insuficiente de alunos para frequentá-las. Ou, ao contrário, como nos casos de atenção à saúde e segurança, pela excessiva demanda criada a partir da reestruturação espacial e novo contingente populacional que acorre ao local para a execução de serviços na instalação das obras das usinas.

Somam-se, assim, às perdas ou dificuldades enfrentadas para os considerados "indiretamente atingidos", nos estudos de impactos ambientais, outro aspecto destacado por Souza (idem), a saber, a reestruturação, ainda que temporária, dos espaços sociais locais e regionais com a vinda de contingentes de trabalhadores para a instalação da obra, que vêm alterar os padrões de sociabilidade, e demandar assistência nos por vezes já precários serviços públicos locais e regionais. Como afirma Souza (1988, p. 122),

\begin{abstract}
$\mathrm{Na}$ medida em que a força de trabalho empregada nas obras é majoritariamente masculina (aproximadamente 90 a $95 \%$ do contingente total), e que destes apenas pequena parte é acolhida com a família, podemse avaliar algumas de suas consequências negativas para a alteração dos padrões demográficos e de sociabilidade local e regional, como é o caso da 'indústria' da prostituição, a qual é fruto da economia da obra como um todo.
\end{abstract}

Do ponto de vista estritamente ambiental, apesar do discurso legitimador de que as hidrelétricas são fontes de energia "limpa, renovável e barata" (ROVERE, 1990; SEVÁ, 2002), alterações significativas e preocupantes têm sido criticamente avaliadas por especialistas de diferentes áreas, e objeto de preocupação de organizações não governamentais como a Comissão Mundial de Barragens. Como destaca Vainer (2008), esta Comissão produziu em 2000 um volumoso e criterioso relatório sobre riscos tecnológicos e efeitos ambientalmente negativos das grandes hidrelétricas. Trata-se da degradação progressiva dos rios barrados, de alterações climáticas e de ameaças de graves acidentes ambientais, já registradas em 
diferentes hidrelétricas nacionais e internacionais, mas pouco divulgados. Do mesmo modo, autores brasileiros como Sevá (2004) e Bermann (2007) especificam diferentes fatores ambientais que podem ocorrer em consequência da instalação de hidrelétricas, como alteração do processo de sedimentação nos rios, tremores de terra e outras atividades sísmicas na região da usina, alterações na composição química, física e térmica da água, aumento da salinização dos solos, alteração do ciclo migratório da ictiofauna, surgimento de focos de doenças endêmicas decorrentes dos pontos de água parada, emissão de gases de efeito estufa, além dos efeitos cumulativos decorrentes da intensificação da construção de barragens em uma mesma bacia hidrográfica, como é o caso de várias destas bacias, no Brasil, dentre as quais a do rio Uruguai (SC/RS) e do Paraná (SP/PR).

Estas e outras implicações ambientais e socioculturais, além de mal dimensionadas, têm sido tratadas pelo Estado brasileiro com negligência e descaso, na maioria dos casos estudados, entre outros, por Santos ${ }^{8}$ (1979; 1983; 2007), Germani (1982), Martins-Costa (1989), Magalhães (1996), Reis (1998) e Bloemer (2005).

Do mesmo modo, várias são as críticas dirigidas ao modo como são realizados os levantamentos e elaborados os relatórios dos EIAs e RIMAs. Dentre as críticas apresentadas por diferentes autores ${ }^{9}$, destaca-se que têm sido elaborados de forma inconsistente, com falta de determinadas informações, omissões, contradições e incorreções sobre os seguintes aspectos socioambientais de cada uma das hidrelétricas em análise: o número de pessoas a serem deslocadas; a existência de populações indígenas, cuja legislação obriga a consulta sobre as alterações em seu território e a aprovação pelo Congresso Nacional; o tipo de atividades que eram desenvolvidas nos locais a serem alagados ou apropriados para outros fins na instalação das hidrelétricas, e a impossibilidade de continuar a manter determinadas práticas produtivas, como a pesca, que seria prejudicada com a formação do lago; a inviabilização de comercialização de determinados produtos; a dificuldade de acesso a certo serviços básicos, como de educação e saúde; o fechamento de escolas e a perda de outros equipamentos e bens comunitários; a dispersão de grupos familiares pelo deslocamento de parte deles, ou o

8 Estes e outros trabalhos de Sílvio Coelho dos Santos, pioneiro nas pesquisas sobre os efeitos socioambientais no Brasil, estiveram preferencialmente voltados para estes efeitos em relação às populações indígenas.

${ }^{9}$ Sobre estas críticas, veja-se, entre outros, a coletânea organizada por Rothman (2008). 
reassentamento em locais distantes uns dos outros; a indefinição sobre as medidas mitigatórias ou compensatórias para o deslocamento da população, ou para compensar perdas parciais de espaço ocupados antes da instalação da hidrelétrica.

Vale ainda destacar que os próprios EIAs e RIMAs tem sido um dos objetos de maior crítica e de disputa do MAB e de outros movimentos sociais, no sentido de exigir correções e complementações que permitam dimensionar criteriosa e criticamente os efeitos socioambientais decorrentes da obra em estudo, para melhor definir e direcionar as possíveis reorientações sobre o projeto em análise, e as mitigações para as populações regionais e locais atingidas.

\section{ESTRATÉGIAS DE NEGOCIAÇÃO COM OS ATINGIDOS POR PARTE DOS RESPONSÁVEIS PELA INSTALAÇÃO DE HIDRELÉTRICAS}

O planejamento e as iniciativas da Eletrosul em relação ao aproveitamento hidroenergético da Bacia do Uruguai foram marcados pelas características básicas que norteavam o setor elétrico brasileiro desde a criação da Eletrobras e que de certo modo perduram até o presente. Ou seja, a existência, desde então, de um portentoso aparelho de planejamento, controle e gestão dos sistemas de produção e distribuição de energia elétrica no conjunto do território nacional (VAINER; ARAÚJO, 1990) e a opção preferencial por grandes usinas de aproveitamento hídrico para o atendimento à demanda de eletricidade.

De acordo com estes autores, em relação às providências relativas à desapropriação e deslocamento das populações ocupantes das áreas destinadas à implantação das hidrelétricas, as subsidiárias da Eletrobras atuavam de modo semelhante, através de três estratégias básicas: a desinformação, a perspectiva territorial patrimonialista, e a negociação individual.

A desinformação, uma das principais estratégias das empresas públicas ou privadas do setor elétrico em seu relacionamento com as populações locais que ocupam as áreas onde elas serão instaladas era, como lembram os referidos autores (VAINER; ARAÚJO, 1990), a forma pura e simples da sonegação de informações. Essa sonegação visava e ainda visa possibilitar o ingresso e a circulação de pessoal da Empresa na região e facilitar a conquista de algumas posições no espaço regional, antes que a população tome conhecimento do que está para acontecer. Esta estratégia continuava, por vezes, após o início das obras, 
através de uma espécie de "propaganda enganosa", veiculada pelo próprio setor que divulgava o empreendimento e seus supostos "benefícios", calando-se quanto aos aspectos socioambientais negativos. Ou, ainda, por meio da divulgação de informações contraditórias ou desencontradas sobre vários aspectos do andamento das obras, entre as quais as soluções relativas ao deslocamento das populações locais, o que facilitaria por parte dos responsáveis pelo empreendimento, ao gerar insegurança e dúvidas, a imposição de determinadas soluções à revelia dos segmentos sociais potencialmente afetados pelos projetos a serem executados.

A estratégia territorial patrimonialista, por sua vez, de acordo com Vainer e Araújo (idem), foi frequentemente utilizada pelo setor elétrico quando se tratava de "criar o vazio demográfico necessário à instalação das barragens". Eram realizados cadastramentos socioeconômicos fornecendo informações sobre cada estabelecimento rural ou urbano e seus respectivos proprietários. Estes dados norteavam, através da compra, a "desocupação" da área e sua reapropriação por parte do setor elétrico, desconsiderando-se os direitos dos demais ocupantes não proprietários dos espaços territoriais ocupados.

De fato, a "indenização em dinheiro" pela terra e posteriormente também por benfeitorias foi preponderante em muitas das grandes hidrelétricas construídas até a década de 1970. Vale destacar, contudo, que o MAB conseguiu, como veremos mais adiante, reverter esta solução tradicional, lutando para incluir a troca de "terra por terra na região", acrescentando posteriormente a possibilidade de "reassentamento coletivo", incluindo com direito a estes reassentamentos também os que não eram proprietários das terras onde moravam e trabalhavam (arrendatários, agregados, posseiros).

Por último, os trabalhos de aquisição das áreas a serem desocupadas eram preferencialmente realizados através de "negociações individuais" entre o proprietário da área requisitada e a Empresa responsável por esta tarefa. Conforme, ainda, os referidos autores, a opção por este tipo de negociação tinha objetivos claros: impedir, ou dificultar, a discussão e organização coletivas, aspectos que foram igualmente revertidos, de certo modo, com a criação do MAB.

No caso específico da instalação de hidrelétricas (UHEs) no vale do Rio Uruguai (SC/RS), cuja proposta ficou popularmente conhecida como Projeto Uruguai, a situação não foi diferente, até o advento do MAB. Em consequência de sua atuação, várias foram as conquistas dos agricultores familiares em relação ao 
seu deslocamento da região, em função da inundação ou perda parcial de suas terras necessárias à instalação das duas primeiras UHEs a serem instaladas - UHE Itá e UHE Machadinho.

\section{A TRAJETÓRIA HISTÓRICA DO MAB: ORGANIZAÇÃO, ESTRATÉGIAS DE LUTA E CONQUISTAS}

Como foi dito anteriormente, a Eletrosul tentou, no Vale do Rio Uruguai, reproduzir, em parte, as referidas práticas até então correntes em relação a outras hidrelétricas implantadas na década de 1970, esquivando-se, inclusive, até onde foi possível, ao diálogo com os agricultores, além de invadir propriedades rurais, provocando danos em cercas e plantações, derrubando árvores e instalando piquetes para demarcar as áreas a serem alagadas pelas UHEs de Itá e Machadino.

Contudo, a reação negativa das populações locais ao Projeto Uruguai, sobretudo de agricultores familiares, especialmente em relação às estas duas primeiras usinas a serem implantadas, ambas no próprio rio Uruguai, localizado no limite entre Santa Catarina e o Rio Grande do Sul, antecipou-se ao início da implantação das obras, o que acabou por interferir no modo tradicional de atuação da própria Empresa. Antecipou-se, de acordo com Reis (1998), porque algumas organizações não governamentais como a Comissão Pastoral da Terra, professores/pesquisadores de uma universidade de Erechim (RS), religiosos vinculados à Diocese de Chapecó, cujo Bispo D. José Gomes foi um grande aliado e militante de causas sociais, e membros de Sindicatos de Trabalhadores Rurais da região souberam extraoficialmente da existência do Projeto Uruguai. Da conjugação e intermediação desses atores sociais, de modo especial de setores da Igreja Católica e dos Sindicatos Rurais, nasceu a rede social que veio a constituir o MAB, cujas lutas e posicionamentos assumiram dimensão nacional e projetaram-se, inclusive, em esferas internacionais dedicadas à problemática em questão.

A história do MAB, embora não ainda com esta denominação, remonta ao ano de 1979, quando por iniciativa da Comissão Pastoral da Terra (CPT), ${ }^{10}$ foi realizada uma primeira reunião na sede do município de Chapecó (oeste catarinense), para

\footnotetext{
${ }^{10}$ A CPT foi fundada em 1975, no período da Ditadura Militar, com a missão de servir os pequenos agricultores, inicialmente na região amazônica. Durante o final de década de 1970 e início da década de 1980 teve uma importante função na assessoria aos movimentos sociais rurais ainda incipientes, à época, no Sul do Brasil.
} 
discutir a problemática em questão. Nesta reunião, estiveram presentes "pequenos produtores do Paraná, de Santa Catarina e do Rio Grande do Sul, representantes da CPT de SC e RS, agentes pastorais, vigários das Igrejas Católicas e Pastores da Igreja Evangélica de Confissão Luterana, Sociólogos e Agrônomos da Fundação do Alto Uruguai para a Pesquisa e Ensino Superior" (FAPES, 1979). Entre outros encaminhamentos feitos nesta ocasião, o mais importante foi a criação de uma "Comissão de Barragens", destinada a refletir sobre o que desde então foi definido como "um problema social" a ser enfrentado pela população regional onde seria desenvolvido o Projeto Uruguai.

Outro aspecto que merece ser registrado é a possibilidade oferecida aos agricultores do Alto Uruguai, a partir deste primeiro evento, de entrar em contato com as experiências vivenciadas por outros produtores rurais quanto à implantação de hidrelétricas. Depoimentos sobre estas experiências foram prestados por agricultores expropriados para a implantação das hidrelétricas de Salto Santiago e Salto Osório, ambas instaladas pela Eletrosul no Estado do Paraná e, posteriormente, da UHE de Itaipu. Neste último caso, é indispensável registrar o surgimento do "Movimento Justiça e Terra", igualmente iniciado pela CPT, em 1978, e que marcou o início da reação dos pequenos agricultores brasileiros à atuação governamental quanto às soluções para seu deslocamento compulsório, frente às referidas estratégias tradicionais do setor elétrico, apresentadas sob a ameaça de encaminhamento judicial, caso não fossem aceitas as suas propostas de negociação (FAPES, 1979).

No caso do Vale do Uruguai, a Comissão de Barragens sofreu sucessivas reestruturações, já no início de sua atuação, em especial em virtude da criação de comissões municipais e locais, passando a ser denominada Comissão Regional de Atingidos por Barragens (CRAB). Em março de 1985, foram criadas quatro comissões regionais ${ }^{11}$, cada uma com a função de coordenar as respectivas regiões, passando a CRAB a ser denominado de Movimento dos Atingidos por Barragens.

A configuração e a dinâmica da reação dos pequenos produtores ao Projeto Uruguai, de acordo com Scherer-Warren e Reis (1986, 1989), sem sombra de dúvida estiveram ligadas à atuação da CRAB, e posteriormente do MAB. Além das iniciativas em termos da organização do Movimento, várias outras foram encaminhadas para mobilizar os agricultores familiares e para pressionar a Eletrosul

${ }^{11}$ Itá/Machadinho; Itapiranga/Irai; Lages/Vacaria; Chapecó/Chapecozinho. 
em relação à problemática em pauta. Foi, assim, divulgada a notícia da implantação das hidrelétricas e desnaturalizadas suas implicações socioambientais, contrapondose ao discurso do progresso e dos benefícios para a região, veiculado pela Eletrosul. Do mesmo modo, através da indicação de "danos e perdas" - especialmente para os agricultores ocupantes das áreas requeridas para os empreendimentos do Projeto Uruguai - foram identificadas as "vítimas" em potencial deste Projeto, politicamente nomeadas de "atingidos". Em linhas gerais, foram buscadas e veiculadas informações sobre as consequências e magnitude do Projeto Uruguai; encaminhadas demandas e reivindicações; definidos inimigos e conquistados aliados, pressionando prefeitos e vereadores a se posicionarem, batendo às portas das Assembleias Legislativas do Rio Grande do Sul e de Santa Catarina, recorrendo a Brasília e encaminhando às autoridades federais um abaixo-assinado de mais de um milhão e meio de assinaturas. Foi também O MAB que organizou grandes romarias e outras manifestações públicas; publicou um jornal - a "Enchente do Uruguai"; assumiu programas de rádio e criou fatos políticos como a retenção de técnicos da Eletrosul, a invasão de acampamentos nos territórios ocupados por essa Empresa, e a arrancada de marcos colocados por seus técnicos. Foi, ainda, através da atuação do MAB que se estabeleceram, em 1987, os termos do Acordo firmado com a Eletrosul em relação às soluções para o deslocamento de produtores familiares, cujas terras seriam afetadas pela instalação, no rio Uruguai (RS/SC), das hidrelétricas Itá e Machadinho. Neste Acordo foram incluídas como alternativas as seguintes possibilidades: indenização financeira, troca de terra por terra, ou reassentamento coletivo, neste último caso de modo especial para os não proprietários das terras ocupadas. (REIS, 1998).

Estas e outras iniciativas do MAB, na Bacia do Rio Uruguai, ocorreram com a presença e articulação de diferentes mediadores políticos, mas como foi dito, especialmente da Igreja Progressista e dos Sindicatos de Trabalhadores Rurais, cuja atuação será comentada a seguir.

\section{A ATUAÇÃO DE DIFERENTES MEDIADORES NA CONSTITUIÇÃO DO MOVIMENTO DOS ATINGIDOS POR BARRAGENS}


Afora a participação direta ou indireta de sua hierarquia e a atuação politicamente engajada dos demais agentes pastorais, alertando nos púlpitos e outros espaços religiosos como as "Comunidades Eclesiais de Base" (CEBs) ${ }^{12}$ sobre as consequências da instalação de hidrelétricas na Bacia do Uruguai, a presença da Igreja foi decisiva também para mobilizar e organizar os pequenos produtores rurais para a problemática em questão, de diversas outras maneiras: colocando à disposição sua infraestrutura física para a realização de eventos, como cursos e assembleias, e intermediando a obtenção de recursos financeiros até mesmo internacionalmente (ROTHMAN, 1993 e 1996). Mas, sobretudo, foi indispensável por sua atuação político-pedagógica voltada para a formação de lideranças, levada a cabo pela "Escola Diocesana de Servidores de Erexim" (ESC), pela Pastoral da Juventude (PJ) e pela Comissão Pastoral da terra (CPT). ${ }^{13}$

Em decorrência do trabalho mobilizador das lideranças preparadas pela Igreja Progressista (DOIMO, 1995), signos de linguagem como "a caminhada", o "povo oprimido" e a "libertação" foram presenças constantes no discurso referente à problemática em pauta, especialmente através da fala de seus agentes em grandes manifestações públicas.

A politização da problemática das barragens através da mediação de agentes religiosos manifestou-se, por outro lado, na apropriação e ressemantização de símbolos cristãos, como é o caso da utilização de cruzes para substituir os marcos colocados pela Eletrosul para definir as áreas a serem alagadas, retirados através de rituais realizados em diferentes localidades da Bacia do Uruguai, no logotipo do próprio MAB, ou sendo tematizada em cânticos entoados nas celebrações religiosas.

Contudo, a partir de meados da década de 1980 a formação de lideranças rurais no Alto Uruguai foi prioritariamente assumida pelas Escolas Sindicais. Em decorrência das várias articulações realizadas nos estados do Sul e do crescimento

\footnotetext{
${ }^{12}$ Como afirmou uma das lideranças da CRAB (Reis, 1998), "as CEBs coincidem com os limites das comunidades rurais tradicionais", constituindo-se em um conjunto de "Círculos Bíblicos" ou "Grupos de Reflexão".

${ }^{13}$ A ESC foi fundada em 1973, em Erexim (RS), cidade que sediava a CRAB, desde seu início. Esta Escola passou, a partir de 1978 (MORAES, 1994), a fornecer cursos para a formação de lideranças, sendo através delas desencadeado um processo de "renovação" nas comunidades coloniais tradicionais. A atuação da Pastoral da Juventude visava, do mesmo modo, uma "formação libertadora", através da realização de cursos como o TAPA (Teologia e Ação Pastoral), tendo como principal objetivo mobilizar politicamente os jovens para analisar "os problemas que aconteciam não só nas comunidades, mas na realidade social". A atuação da CPT visava, também, a preparação político-pedagógica dos pequenos agricultores, realizando seus "mutirões de formação", ou seja, de preparação para a luta política. (MORAES, idem, p.151).
} 
de suas atividades, foi mantida, entre 1985 e 1987, a "Escola Sindical Margarida Alves" (ESMA), por onde passaram muitos dirigentes dos movimentos sociais do Alto Uruguai. Os conteúdos da formação de lideranças rurais repassados pela ESMA estavam voltados para a perspectiva da transformação social, na direção da construção de uma nova sociedade. Conforme Moraes (1994), ela orientava com a perspectiva de conscientizar as lideranças sobre a realização de um projeto externo e muito mais amplo de transformação da sociedade, de capitalista em socialista. Aproximava-se, assim, mais do perfil de um partido político, perfil que a rigor deveria orientar a concepção de movimento social, ${ }^{14}$ inclusive o da CRAB, como será mostrado adiante.

No início de 1987 foi criada a Escola Sindical Alto Uruguai (ESAU), com a finalidade de desenvolver a formação dos movimentos populares, urbanos e rurais da região em questão, além de três outras do Rio Grande do Sul, com modelo organizativo e projetos políticos similares aos da ESMA (MORAES, 1994). Entretanto, como informa esta autora (idem), no início dos anos de 1990, uma vez que as escolas sindicais estavam distanciadas da realidade imediata e das demandas específicas dos movimentos sociais, o trabalho de formação foi deixado para as "instâncias", ou seja, os próprios movimentos ou organizações, o que já vinha sendo realizado pelo Movimento dos Sem-Terra e iniciado, inclusive, pelo próprio MAB, no Vale do Uruguai.

Esta reorientação no modo de conduzir as tarefas de formação, de acordo com Moraes (idem), também alterou a relação com outros mediadores, ou seja, as entidades de apoio como o "Centro de Educação Popular" (CEPO) $)^{15}$, fundado em 1986, e o "Centro Vianei de Educação Popular", criado pela Diocese de Lages (SC). No mesmo ano da criação do CEPO foi instalado no Alto Uruguai o "Centro de Tecnologia Alternativa" (CETAP), em um encontro organizado pela Federação de Órgãos para Assistência Social e Educacional (FASE). O Centro foi criado com os objetivos de difundir técnicas que se adaptassem à pequena propriedade, prestar

\footnotetext{
${ }^{14}$ Como afirma Navarro (1996), havia antes mesmo da criação da ESMA uma forte identificação entre as lideranças do "novo sindicalismo", no Alto Uruguai, e a formação dos diretórios municipais do Partido dos Trabalhadores (PT).

${ }^{15}$ O CEPO que foi destinado a exercer tarefas como a formação de lideranças, a preparação de material para comunicação - inclusive o Jornal "A Enchente do Uruguai" - e a intermediação para a obtenção de recursos financeiros do exterior (SCHERER-WARREN; REIS, 1989), concentrou-se, então, na prestação dos demais serviços e menos nas tarefas de formação.
} 
serviço de assessoria na área tecnológica às organizações e movimentos ligados à pequena propriedade e treinar e capacitar técnicos e produtores.

Por outro lado, o papel das assessorias técnicas, entre as quais se incluía a presença de especialistas de diferentes áreas de conhecimento (agrônomos, sociólogos, geógrafos, advogados etc.), foi fundamental para capacitar o MAB a lidar com um amplo conjunto de demandas e questões que o desafiavam a transitar pelo universo da política energética, pelos aspectos técnicos relativos à construção de usinas hidrelétricas e suas consequências socioambientais, ou pelo planejamento e instalação de projetos de assentamentos rurais.

É indispensável destacar, contudo, que as mudanças que marcaram a passagem da maior presença da mediação da Igreja Progressista para a do sindicalismo, no Movimento das Barragens, não ocorreram em bloco e, ao mesmo tempo, nem ao menos no mesmo ritmo em toda a região. Foram, entretanto, os mesmos agentes que frequentaram a Escola Diocesana de Servidores de Erexim (ESC) que em sua grande maioria constituíram o público privilegiado das escolas sindicais. Foram eles mesmos que organizaram as oposições sindicais, iniciaram o Movimento dos Sem-Terra, criaram as Comissões de Barragens e o Movimento das Mulheres Agricultoras, e neles atuaram, por vezes simultaneamente, tornando-se ainda representantes da Central Única dos Trabalhadores (CUT), membros e até candidatos do Partido dos Trabalhadores. Atuaram, portanto, ao longo de suas histórias particulares em vários desses movimentos e instituições, carregando consigo as marcas de sua formação e diferentes experiências vivenciadas por onde passaram atuando politicamente. (SCHERER- WARREN; REIS, 1989)

Os reflexos da transformação da CRAB-MAB de "serviço", como propunha a Igreja Progressista, em "movimento", ocorrida a partir de 1985, intimamente associada à predominância de princípios organizativos propostos pelo sindicalismo combativo, tornaram-se evidentes, conforme Reis (1998), através de maior concentração do poder de decisão nas mãos de um grupo dirigente. Como parte dessa postura vanguardista ocorreram modificações na perspectiva do Movimento quanto aos objetivos de sua atuação e da própria luta política. No primeiro aspecto, tratava-se de promover a consciência política nos pequenos produtores rurais. No segundo, de promovê-la com o propósito de reconhecer sua condição de trabalhadores rurais, ameaçados de perder a terra. Significou ainda um progressivo afastamento das práticas e representações simbólicas inspiradas no universo 
religioso praticamente hegemônico no período anterior, marcado pela intermediação da Igreja Progressista.

Em termos práticos, as mudanças na organização do MAB desembocaram em propostas relativas ao deslocamento compulsório a que seriam submetidos os produtores rurais, firmadas através do referido Acordo, assinado em 1987, sem dúvida a maior conquista do Movimento até aquele momento.

De fato, uma das primeiras tarefas assumidas pela CRAB, quando de sua constituição, foi a obtenção e a veiculação de informações sobre o deslocamento da população ocupante das áreas a serem requeridas para a instalação da infraestrutura necessária ao funcionamento das duas hidrelétricas a serem construídas - UHE de Itá e UHE Machadinho.

Desde as primeiras reuniões entre lideranças e pequenos produtores rurais tornou-se evidente a desinformação das populações locais sobre as referidas obras. Assim, "informar para mobilizar" a partir destes primeiros encontros, ainda que não explicitamente, transformou-se em uma das prioridades do trabalho dos mediadores.

As informações a serem veiculadas diziam respeito tanto a aspectos técnicos que adquiriam importância social - como a definição das cotas dos lagos das barragens que permitiriam dimensionar as áreas que seriam alagadas - quanto o conhecimento sobre a atuação da Eletrosul e de outras subsidiárias da Eletrobras em relação às questões sociais, podendo incluir, o que frequentemente ocorreu, considerações sobre a questão das barragens e a produção de energia e sua inserção no contexto nacional e internacional.

Quanto aos dados técnicos sobre o Projeto Uruguai, foram feitos sucessivos apelos a Eletrosul para que fossem definidos, entre outros aspectos, as áreas a serem alagados, e o número da população a ser atingida. Poucas informações, entretanto, eram fornecidas pela empresa, e menos ainda se sabia sobre o destino das populações ocupantes destas áreas.

Porém, em resposta a um pedido de definição por parte dos prefeitos do Alto Uruguai, a Eletrosul encaminhou o documento Política Geral de Desapropriações, em 1981, no qual foram explicitadas as condições em que deveria ocorrer o deslocamento das populações das áreas a serem requeridas pela Empresa. Entretanto, embora fossem apontadas, neste documento, como soluções para a liberação das áreas requeridas, tanto a possibilidade de reassentamento quanto a indenização financeira, ambas as soluções seriam oferecidas aos "proprietários", 
cujas terras fossem compradas pela empresa, desde que existissem documentos comprobatórios de propriedade. A situação dos "posseiros" - incluindo-se aí também arrendatários de terras - seria resolvida pelos governos estaduais envolvidos (SC/RS) e o INCRA (ELETROSUL, 1981). O documento acrescentava outras informações sobre as indenizações e nada mais de incisivo sobre a possibilidade de reassentamento.

À visão patrimonialista da Eletrosul, entretanto, o MAB reagiu, desde muito cedo, com a inclusão em seus questionamentos dos segmentos dos pequenos produtores não proprietários de terras, atribuindo à Empresa a responsabilidade de reassentá-los . A rigor, o destino de todos os pequenos produtores rurais, proprietários ou não, diante da possibilidade de desapropriação tornou-se o objeto central da preocupação dos dirigentes do MAB e motivo da mobilização e organização dos futuros atingidos. Preocupação que foi traduzida em "bandeiras de luta" (FAPES, 1979), tendo como horizonte garantir, de um modo ou de outro, diante da ameaça de migração compulsória a que seriam submetidos, o acesso à terra, e através dele condições de continuar garantindo sua reprodução social como produtores rurais.

A primeira reivindicação ou bandeira de luta assumida pelo MAB desde o primeiro Encontro de 1979 foi a "indenização justa" pelas terras e benfeitorias. A adjetivação "justa" foi acrescentada à solução tradicional de desapropriação proposta pelo setor elétrico em situações similares, tendo em vista os depoimentos, já aludidos, dos pequenos produtores do Paraná.

Se "justa", neste caso significava de conformidade com os valores do mercado de terras nas regiões em questão, em um documento - Manifesto dos pequenos produtores do Alto Uruguai Gaúcho e Catarinense sobre as Barragens elaborado alguns meses depois da reunião em Chapecó, esta qualificação foi ressemantizada ou teve seu conteúdo ampliado, atribuindo à terra um valor simbólico, estimativo, quando foi afirmado que "Em cima de nossas terras colocamos tudo. Para nós elas têm um valor que a técnica não percebe". (COMISSÃO DE BARRAGENS, 1980). Este "tudo", cujo valor os técnicos não consideravam, dizia respeito a outros valores agregados a terra, além de sua condição de meio de produção, tais como o trabalho nela investido, suas tradições e sua vinculação a espaços comunitários. 
Por estas e outras razões apontadas no documento em questão, contraditoriamente, afirma-se, mais adiante, que "terra se troca por terra e não por dinheiro". Ou seja, à "indenização justa" agregou-se uma nova reivindicação, já insinuada na reunião de Chapecó: “terra por terra na região”. A rigor, as principais razões para colocar em questionamento a desapropriação através de compensação financeira eram, em primeiro lugar, o temor de perder o acesso à terra devido a provável desvalorização das quantias recebidas em função das altas taxas de inflação e, em segundo lugar, a possibilidade de serem deslocados para outras regiões. Este último temor foi confirmado quando a Eletrosul acenou com a possibilidade de realizar reassentamentos através de projetos para tal finalidade, localizadas no Mato Grosso.

Como lembra Moraes (1994 a), a tensão entre as duas propostas, "indenização justa" e "terra por terra na região", perdurou por alguns anos ao longo da trajetória do MAB. Se havia, contudo, tensão entre as duas propostas e mesmo ambiguidade e indefinição, não havia dúvida sobre o modo como deveriam ser encaminhadas as negociações. À imposição da Eletrosul de que as negociações fossem realizadas sem nenhuma intermediação, o MAB respondeu, desde os primeiros encontros, com veemente apelo aos pequenos produtores de que não negociem suas terras individualmente. Por outro lado, a reivindicação por reassentamento na região, ainda que de maneira indireta e mal delineada, apareceu já no Manifesto de Concórdia (CRAB, 1980). Foi, entretanto, no Comunicado resultante de uma reunião da Comissão Regional, realizada em agosto de 1980, que se explicitou a proposta de reassentamento, incluindo nela os que "não possuem terra, posseiros, arrendatários, peões, parceiros, índios, etc." (CRAB, 1980 a).

Por parte da CRAB, pelo menos até 1983, considerando que as providências prometidas pela Eletrosul em relação às questões sociais não foram cumpridas, além do aprofundamento das discussões sobre as reivindicações como as condições para o encaminhamento das indenizações e reassentamentos, cresciam qualitativamente as discussões sobre "barragens porque e para quem", incluindo cada vez mais argumentos macroeconômicos (SCHERER-WARREN; REIS, 1986). Contudo, movidos pela incerteza, pelo medo e pela indignação diante do que, em síntese, classificavam como "descaso do governo", não surpreende a radicalização do Movimento ao lançar, paralelamente as demais bandeiras de luta, um "Não às Barragens". 
Este posicionamento foi assumido também a partir de um grande evento realizado na Assembleia Legislativa do Rio Grande do Sul, congregando diferentes segmentos sociais e políticos, além dos agricultores do Vale do Uruguai. Neste evento, juntamente com o repúdio ao Projeto Uruguai, foi aprovada a proposta de elaboração de um abaixo-assinado contra as barragens a ser encaminhado ao então Presidente da Eletrobras e ao titular do Ministério Extraordinário de Assuntos Fundiários (CRAB, 1984 a).

Contraditoriamente, o ano de 1985 foi identificado pelo MAB, além da manutenção do "Não às Barragens", pela luta para participar nas decisões sobre o destino da proposta da Eletrosul de implantação das referidas hidrelétricas. Assim que se instalou a Nova República, um grupo de parlamentares gaúchos foi a Brasília e obteve do então Ministro das Minas e Energia, Aureliano Chaves, a promessa de suspensão temporária dessa proposta, para que fossem reestudadas as suas condições. ${ }^{16}$ Ao mesmo tempo, em audiência posterior mantida com representantes do MAB, o referido Ministro prometeu a constituição de uma comissão para estudar o Projeto Uruguai e a paralisação temporária deste Projeto, ambas as conquistas saudadas com entusiasmo no Alto Uruguai.

Ao longo de 1986, entre marchas e contramarchas, o MAB dedicou-se a implementar uma longa rodada de reuniões nas localidades a serem alagadas pela UHE Itá e UHE Machadinho, discutindo propostas concretas em relação ao deslocamento dos agricultores destas localidades. As discussões foram, por fim, sintetizadas em um importante documento - o "Documento de Getúlio" - elaborado em um grande encontro realizado no município de Getúlio Vargas (RS) (CRAB, 1986), contendo 39 pontos a serem contemplados pela Eletrosul.

Depois de muitas tentativas frustradas de negociar os referidos pontos com a Empresa, o diálogo foi iniciado através de uma correspondência endereçada à CRAB sinalizando positivamente para vários deles e argumentando contra outros. Mas, sobretudo, assumindo compromissos, como a busca de soluções para os atingidos sem terra, a negociação coletiva em relação às indenizações e a apresentação de áreas nos três estados do Sul para os atingidos que optassem por "terra por terra". O consenso em torno do Documento de Getúlio ocorreu, finalmente, em uma Assembleia Regional dos atingidos da Região I que contou com a

\footnotetext{
${ }^{16}$ Conforme a Gazeta Mercantil de 13/04/1985, (apud CRAB, 1985 ), esta promessa teria provocado a renúncia do então Presidente da ELETROSUL, Thompson Flores.
} 
participação de diretores da Eletrosul. Este documento, que passou a ser referido genericamente de "Acordo" - Documento de Acordo entre a ELETROSUL e a $C R A B$, em relação às Usinas Hidrelétricas de Itá e Machadinho - foi assinado pelo Presidente da Empresa, em 29 de outubro de 1987, e pelo Ministro das Minas e Energia, em 6 de novembro do mesmo ano. (REIS, 1998).

A partir de 1988, o MAB voltou-se para questões relativas aos futuros reassentamentos decorrentes da instalação da UHE Itá, como a escolha, juntamente com a Eletrosul, das glebas a serem adquiridas; a participação em uma Comissão para definir critérios e montar os projetos para a instalação desses reassentamentos; a tarefa de mobilizar, informar e tentar convencer os colonos não proprietários a optarem por essa alternativa; a realização de reuniões com os optantes para discutir o modelo de organização da produção e o perfil tecnológico a serem implantados na retomada do processo produtivo; a coordenação de parte do processo de instalação da infraestrutura desses empreendimentos. Assumiu, também, um conjunto de tarefas visando o cumprimento do referido Acordo, fazendo levantamentos semestrais do preço das terras na região para orientar as negociações das indenizações e participando em uma "Comissão Paritária", juntamente com a ELETROSUL, destinada a discutir situações especiais (como doença, velhice etc.) de determinadas famílias que não poderiam ser removidas da região do Alto Uruguai.

Além de todas essas incumbências, o MAB abriu novas frentes de luta, contribuindo decisivamente para a mobilização de outros futuros atingidos em reação à instalação de hidrelétricas em outras regiões e outros estados brasileiros. Foi, de modo especial, um dos organizadores do I Encontro Nacional sobre Barragens (Goiânia, 1989), que deu origem a uma nova articulação nacional de outros movimentos em torno do mesmo problema, sendo criado o MAB nacional, e estabelecido o dia 14 de marco como o Dia Nacional de Luta Contra as Barragens. A este Encontro sucederam-se outros nos anos posteriores, dois deles $(1997,2003)$ de caráter internacional, resultantes da articulação do MAB com uma rede de organizações voltadas para a problemática em questão.

Simultaneamente, além da participação em um número crescente de fóruns como o Fórum Nacional da Reforma Agrária; em redes inter-organizacionais como a Inter-Redes e a Via Campesina; em articulações mais amplas como a Semana Social Brasileira, e a Assembléia Nacional Popular, participou de articulações 
transnacionais como o Fórum Consultivo da Comissão Mundial de Barragens e o Committee on Dams, Rivers and People, dentre outras.

$\mathrm{Na}$ mesma linha de posicionamento político, o MAB, em fevereiro de 2003, entregou ao Ministério de Minas e Energia uma pauta de reivindicações compreendendo duas dimensões : uma em prol da solução dos problemas sociais ocasionados pelas barragens já construídas, como a necessidade de fornecimento de alimentação às famílias que estariam passando fome, porque foram removidas de suas terras, sua principal fonte de renda; outra, sugerindo mudanças estruturais do modelo energético brasileiro. O "Dossiê: ditadura contra as populações atingidas por barragens aumenta a pobreza do povo brasileiro" (MAB, 2004), sintetiza de forma inequívoca as três dimensões que o MAB foi desenvolvendo em sua trajetória, isto é, a de reparação das consequências sociais negativas para as populações atingidas pelas barragens; as consequências no meio ambiente impactado pelas obras das hidrelétricas, e as consequências de um modelo de planejamento energético e a necessidade de modificações nesse modelo. No Dossiê também fica explicitada a articulação do MAB com o movimento popular brasileiro desse novo milênio, comprometido com os mais excluídos, e com um novo projeto de desenvolvimento. (SHERER-WARREN; REIS, 2008).

Resta constar, diante da retrospectiva da história do MAB, como já foi dito (REIS, 2009), que muitas foram suas conquistas ao longo de seus quase trinta anos de existência. Entretanto, o MAB e as populações locais e regionais ocupantes dos espaços reestruturados para a instalação de hidrelétricas tiveram e continuando a ter que enfrentar novos desafios decorrentes da privatização de parte do setor elétrico, a partir da década de 1990. Sem dúvida, como atestam diversas pesquisas acadêmicas, desde então tem sido registrado significativo retrocesso no que concerne às questões socioambientais, dentre as quais as relativas às soluções para o deslocamento compulsório das populações em decorrência da instalação de hidrelétricas. Mais que isso, lideranças do MAB e agricultores familiares atingidos têm enfrentado repressão policial e indiciamento judicial, como nos casos da UHE de Campos Novos (SC) (KROEGER, 2005), e da UHE de Foz do Chapecó (FELIPE, 2011; e ROCHA, 2012), ambas instaladas na região do Alto Uruguai (RS/SC).

Para finalizar, cabe aqui endossar o apelo de Vainer $(2007$, p. 122) para que sejam colocadas em discussão as repercussões da reestruturação e privatização do setor elétrico. Por um lado, em relação ao já referido retrocesso em relação às 
questões socioambientais. Por outro, como recomenda o autor, no sentido de garantir às populações atingidas e à sociedade brasileira de um modo geral, uma efetiva participação nestas discussões, a meu ver na perspectiva da busca de novos encaminhamentos para a produção de energia elétrica, de um modo socialmente mais justo e ambientalmente responsável. 


\section{REFERÊNCIAS}

BERMANN, Célio. Impasses e controvérsias da hidreletricidade. Estudos Avançados, São Paulo, v. 21, n. 59, 2007.

BLOEMER, Neusa S. Brava gente brasileira: migrantes italianos e caboclos nos Campos de Lages. Florianópolis: Cidade Futura, 2000.

BOURDIEU, P. ; SAIAD, S. Le déracinement. La crise de l'agriculture tradicionele em Algérie. Paris: Minuit, 1964.

COMISSÃO REGIONAL DE ATINGIDOS POR BARRAGENS (CRAB). Manifesto dos agricultores do Alto Uruguai gaúcho e catarinense sobre as barragens. Concórdia, 1980.

COMISSÃO REGIONAL DE ATINGIDOS POR BARRAGENS. A Enchente do Uruguai. Barragens: as verdades que a Eletrosul não diz. Erexim, 1984.

COMISSÃO REGIONAL DE ATINGIDOS POR BARRAGENS. A Enchente do Uruguai, Erexim, n. 9, ago. 1984 a.

COMISSÃO REGIONAL DE ATINGIDOS POR BARRAGENS. A Enchente do Uruguai, Erexim, n. 10, abr. 1985.

COMISSÃO REGIONAL DE ATINGIDOS POR BARRAGENS. A Enchente do Uruguai, Erexim, n. 14, mar./abr. 1986.

COMISSÃO REGIONAL DE ATINGIDOS POR BARRAGENS. Comunicado. Marcelino Ramos, 1980a.

DIAS, R. F. et al. Panorama do setor de energia elétrica no Brasil. Rio de Janeiro: Centro de Memória da Eletricidade no Brasil, 1988.

DOIMO, Ana Maria. A vez e a voz do popular. Movimentos sociais e participação política no Brasil pós 70. Rio de Janeiro: Relume-Dumará/ ANPOCS, 1995.

ELETROBRAS. Manual de Estudos e Efeitos Ambientais no Setor Elétrico. Brasília, 1986. 
ELETROSUL. Política Geral de Desapropriação. Florianópolis, 1981.

FELIPE, Marina Reche. Limitações dos Estudos e dos Relatórios de Impacto Ambiental: o EIA/RIMA da Usina Hidrelétrica de Foz do Chapecó. 2010. Trabalho de Conclusão de Curso (Graduação em Ciências Sociais) - Universidade Federal de Santa Catarina, Florianópolis, 2010.

FUNDAÇÃO ALTO URUGUAI PARA PESQUISA E ENSINO SUPERIOR (FAPES). Relatório do Encontro sobre barragens. Chapecó, 1970.

GERMANI, Guiomar. I. Os expropriados de Itaipu. Cadernos do PROPUR, Porto Alegre, 1982.

KROEGER, Juliana. O drama dos atingidos pela barragem de Campos Novos. Caros Amigos, São Paulo, n. 101, ago. 2005.

\section{MAB. Edição Especial do Informativo do Movimento dos Atingidos por} Barragens. 2004.

MAGALHÃES, Sonia. O desencantamento da beira: reflexões sobre a transferência compulsória provocada pela usina hidrelétrica de Tucurui. In: MAGALHÃES, S. et al (Orgs.) Energia na Amazônia. Belém (PA): Museu Paranaense Emílio Goeldoi/Universidade Federal do Pará/Associação das Univ. Amazônicas, 1996.

MARTINS-COSTA, Ana Luisa B. Uma retirada insólita: a representação camponesa sobre a formação do Lago de Sobradinho. 1989. Dissertação (Mestrado em Antropologia Social) - Museu Nacional, Universidade Federal do Rio de Janeiro, Rio de Janeiro, 1989.

MORAES, Maria Stela M. de. No rastro das águas: pedagogia do Movimento dos Atingidos pelas Barragens da Bacia do rio Uruguai (RS/SC) - 1978/1990. 1994. Tese (Doutorado em Educação) - Pontifícia Universidade Católica (PUC), Rio de Janeiro, 1994.

MORAES, Maria Stela M. de. Reassentamentos de atingidos pelas barragens da Bacia do Rio Uruguai. In: MEDEIROS, L. et al (Orgs.) Assentamentos Rurais. Uma visão interdisciplinar. São Paulo: Ed. da UNESP, 1994 a. 
NAVARRO, Zander. Democracia, cidadania e representação: os movimentos sociais rurais no estado do Rio Grande do Sul, Brasil, 1978-1990. In: NAVARRO, Zander et al (Orgs.). Política, protesto e cidadania no campo. As lutas sociais dos colonos e trabalhadores rurais no Rio Grande do Sul. Porto Alegre: Ed. UFRGS, 1996.

OLIVEIRA FILHO, João Pacheco. O nosso governo: os Ticuna e o regime tutelar. São Paulo: Marco Zero/MCT/CNPq, 1988.

REIS, Maria José. Espaços vividos, migração compulsória, identidade: os camponeses do Alto Uruguai e a Hidrelétrica de Itá. 1998. Tese ( Doutorado em Ciências Sociais) - Instituto de Filosofia e Ciências Humanas, Universidade Estadual de Campinas, Campinas, 1998.

REIS, Maria José. A instalação de hidrelétricas no Vale do Rio Uruguai e a constituição de um campo social de conflitos. Ilha - Revista de Antropologia, Florianópolis, v. 10, n. 1, 2009.

REIS, Maria José. Estado, hidrelétricas e sociedade: implicações políticoideológicas. In: CONGRESSO BRASILEIRO DE ECONOMIA E SOCIOLOGIA RURAL, 29, 1991, Campinas. Anais... Campinas, 1991.

REIS, Maria José; BLOEMER, Neusa M. S. (Orgs.). Hidrelétricas e populações locais. Florianópolis: Cidade Futura; Ed. da UFSC; PPGAS, 2001.

RIBEIRO, Gustavo L. Poder, redes e ideologia no campo do desenvolvimento. Novos Estudos. CEBRAP. Março, 2008.

RIBEIRO, Gustavo L. Proyectos de grand escala: Hacia um marco conceptual para el análisis de uma forma de producción temporária. In: BARTOLOMÉ, L. (Org.)

Relocalizados: antropologia social de las poblaciones desplazadas. Buenos Aires:

Ed. del IDES, 1985. (Colección Hombre y Sociedad, n.3).

ROCHA, Humberto José. Relações de poder na hidreletricidade: a instalação da UHE Foz do Chapecó na Bacia do Rio Uruguai. 2012. Tese (Doutorado em Ciências Sociais) - Instituto de Filosofia e Ciências Humanas, Universidade Estadual de Campinas, Campinas, 2012.

ROTHMAN, Franklin D. (Org.).Vidas alagadas: conflitos socioambientais, licenciamento e barragens. Viçosa: Ed. UFV, 2008. 
ROTHMAN, Franklin D. A emergência do movimento dos atingidos pelas barragens do rio Uruguai, 1979-1983. In: NAVARRO, Z. (org.). Política, protesto e cidadania no campo. As lutas sociais dos colonos e dos trabalhadores rurais no Rio Grande do Sul. Porto Alegre: Universidade Federal do Rio Grande do Sul, 1996.

ROTHMAN, Franklin D. Political process and peasant opposition to large hydroelectric dams: the case of the rio Uruguai movement in southern Brazil, 1979 to 1992. 1993. $439 \mathrm{f}$. Tese (Doctorado em Sociologia), University of WisconsinMadison, 1993.

ROVERE, E. L. O planejamento do setor elétrico brasileiro. Revista do Migrante, ano III, n.6, jan./abr., 1990.

SAHLINS, M. Historical metaphors and mythical realities. Michigan: Michigan Press, 1981.

SANTOS, Sílvio C. dos. Hidrelétricas e suas consequências socioculturais. In: VERDUM, Ricardo. (Org.). Integração, usinas hidrelétricas e impactos ambientais. Brasília: Inesc, 2007.

SANTOS, Sílvio C; ASPELIN, Paul. Uruguay Basin Projetc: damming the indians of Southern Brazil. Anthropology Resource Center Newsletter, Boston, v. 3, n.4, 1979.

SANTOS, Sílvio C; NACKE, Aneliese (Orgs.). Hidrelétricas e povos indígenas. Florianópolis: Letras Contemporâneas, 2003.

SANTOS, Sílvio C; REIS, Maria José (Orgs.). Memória do Setor elétrico na Região Sul. Florianópolis: Ed. da UFSC, 2002.

SCHERER-WARREN, Ilse. As barragens do Uruguai: dinâmica de um movimento social. Boletim de Ciências Sociais, Florianópolis, n. 42, 1986.

SCHERER-WARREN, Ilse. O movimento dos atingidos pelas Barragens do rio Uruguai: unidade e diversidade. Cadernos do CEAS, Salvador, n. 120, 1989.

SCHERER-WARREN, Ilse; REIS, Maria José. Do local ao global: a trajetória do Movimento dos Atingidos por Barragens e sua articulação em redes. In: ROTHMAN, Franklin D. (Org.).Vidas alagadas: conflitos socioambientais, licenciamento e barragens. Viçosa: Ed. UFV, 2008. 
SEVÁ FILHO, A. O. Desfiguração do licenciamento ambiental de grandes investimentos. Comunicação apresentada no II Encontro Nacional da ANPPAS, maio de 2004.

SEVÁ FILHO, A.. O. Tópicos de energia e ideologia no início do século XXI: desenvolvimentismo como panaceia? Sustentabilidade como guia de corporações poluidoras? In: ENCONTRO NACIONAL DA ANPPAS, 1, 2002, Indaiatuba. Anais... Indaiatuba: ANPPAS, 2002.

SIGAUD, Lígia. Implicações sociais da política do setor elétrico. In: SANTOS, L.; ANDRADE, L. As hidrelétricas do Xingu e os povos Indígenas. São Paulo: Comissão Pró-Índio de São Paulo, 1988.

SOUZA, Angela T. Os trabalhadores na Amazônia Paraense e as grandes barragens. In: SANTOS, Leinad; ANDRADE, Lúcia. As hidrelétricas do Xingu e povos indígenas. São Paulo: Comissão Pró-Indio de São Paulo, 1988.

VAINER, Carlos B. O conceito de "atingido": uma revisão do debate. In: ROTHMAN, F. D. Vidas Alagadas: conflitos socioambientais, licenciamento e barragens. Viçosa: UFV, 2008.

VAINER, Carlos B. Recursos hidráulicos: questões sociais e ambientais. Estudos Avançados, São Paulo, v. 21, n. 59, 2007.

VAINER, Carlos B.; ARAÚJO, Frederico G. B. Implantação de grandes hidrelétricas: estratégias do setor elétrico, estratégias das populações atingidas. Revista

Travessia, n. 6, jan./abr., 1990.

VIANA, Aurélio. Hidrelétricas e meio ambiente. Doc. 3. Publicações do CEDI. Rio de Janeiro, 1989.

Dossiê:

Recebido em: 01/06/2012

Aceito em: 10/07/2012 